\title{
LEADERSHIP AND INNOVATION IN ORGANIZATIONS: A SYSTEMATIC REVIEW OF FACTORS THAT MEDIATE OR MODERATE THE RELATIONSHIP
}

\author{
LEIF DENTI* \\ Department of Psychology/Gothenburg Research Institute \\ University of Gothenburg, Box 500, 405 \\ 30, Gothenburg, Sweden \\ University of Skövde, Sweden \\ leif.denti@gu.se \\ SVEN HEMLIN \\ Department of Psychology/Gothenburg Research Institute \\ University of Gothenburg, Box 600, 405 \\ 30, Gothenburg, Sweden \\ University of Skövde, Sweden \\ sven.hemlin@gri.gu.se
}

\begin{abstract}
A leader supports teams and individuals as they turn their creative efforts into innovations (leader as facilitator) and manages the organization's goals and activities aimed at innovation (leader as manager). This review focuses on when and how leadership relates to innovation (i.e., the factors that moderate or mediate the relationship between leadership and innovation). The sample consists of 30 empirical studies in which leadership is treated as the independent variable and innovation as the dependent variable. In addition to reviewing moderating and mediating factors, we identified two factors where the findings are ambiguous. The review proposes three new factors that may mediate or moderate the relationship between leadership and innovation.
\end{abstract}

Keywords: Leadership; innovation; creativity; LMX; leader member exchange; transformational leadership; transactional leadership; review.

Fifty years ago, Burns and Stalker (1961) published their influential work on management and innovation. Since then, much work has been done on leadership in innovative endeavors which has lead to the conclusion that leaders are an

*Corresponding author. 
essential element in the promotion of organizational innovation (Hemlin, 2006a; Hülsheger et al., 2009; Mumford et al., 2002). We have now come to the point where more and more research is being directed into understanding when leadership is effective, i.e., under which circumstances at the individual, team and organisational levels, and how leaders influence innovative outcomes, i.e., the various processes and mechanisms of influence. These are the variables that moderate and mediate the relationship between leadership and innovation. This paper reviews the state of research into these moderator and mediator variables.

We view innovation in organisations as an outcome of individual, team, and organisational efforts joined to produce a new product, process, or service that is potentially attractive to a market. Innovation is then the result of a number of activities performedat different levels of the organisation and in its external world. We find the following definition of innovation useful: "the implementation of a new or significantly improved product (good or service), or process, a new marketing method, or a new organisational method in business practices, workplace organization or external relations" (OECD, 2005:46).

Sometimes innovation and creativity are used interchangeably in the literature (Basadur, 2004; Csikszentmihalyi, 1999). However, creativity is commonly viewed as idea generation (ideation) while implementation of ideas is innovation (Amabile et al., 1996; Anderson et al., 2004; Scott and Bruce, 1994). In this paper our focus is on innovation studies, but we also examine research that investigates innovation in terms of creativity when it is clear that innovation was the goal. ${ }^{1}$

\section{The dual process of managing innovation}

We believe that leadership is an integral part of innovative organisational performance for at least two reasons. First, leaders construct the environments that favour creativity and ultimately innovation (Hemlin et al., 2008; Shalley and Gilson, 2004). Much of the leadership research focuses on the essential leadership actions in this construction of context and opportunities that promote the bottomup process of innovation. Leaders encourage intrinsic motivation (Avolio et al., 1999), facilitate problem solving (Tierney et al., 1999), foster a positive team climate (Anderson and West, 1998), and establish and maintain high quality work relationships with team members (Olsson et al., 2008; Scott and Bruce, 1994).

Second, in a top-down process, leaders manage the strategic innovation goals and activities of their organizations. Leaders may set these goals and direct these activities by managing time, facilities, money, and knowledge resources (Drazin et al., 1999), by setting and managing individual and team goals, by defining

\footnotetext{
${ }^{1}$ In Denti and Hemlin (forthcoming), we review the mechanisms leaders use to promote creativity not included in this paper.
} 
expectations for creative performance (Shalley and Gilson, 2004), by managing rewards (Mumford and Gustafson, 1988), and by granting autonomy to individuals and teams (Hemlin, 2006b; Hunter et al., 2007).

Thus, the leader orchestrates the dual process (a) of providing support to teams and individuals as they turn their creative efforts into innovations (leader as facilitator), and (b) of managing the organization's goals and activities aimed at innovation (leader as manager) (see Hemlin, 2006b).

\section{Scope of this study}

Although leaders have a significant impact on innovation activities, they don't work in a vacuum. First, researchers have pointed to the power of the context, with its contingency factors, that may interact with leaders' efforts to stimulate and manage innovation (Bass and Riggio, 2006; Hunt and Conger, 1999; Mumford et al., 2002; Shalley and Gilson, 2004; Yukl, 1999). The contingency factors tell us when leadership relates to innovation (i.e., the circumstances), thus they moderate the relationship between leadership and innovation outcomes. Second, we need more knowledge about the mechanisms leaders use to influence innovation. These are subsumed under another category of factors that mediate leadership and innovation, and they may tell us how leaders influence innovation (i.e., the leaders' influence at the individual, team, and organisational levels).

This paper reviews the factors by which leadership relates to innovation at the individual, team, and organisational levels of human behavior. Among others, Mumford et al. (2002), Oke et al. (2009), and Isaksen and Tidd (2006) have addressed these factors in their research. However, there are few systematic reviews of the empirical research that compile our current knowledge on the mediating and moderating factors between leadership and innovation. For example, whereas Elkins and Keller (2003) studied only the effects of leadership on various outcomes in $\mathrm{R} \& \mathrm{D}$, we take a broader approach. We also extend the work of Ford (1996) and Woodman et al. (1993) by examining more recent research. Also, our approach to drawing inferences about moderating and mediating variables differs from previous reviews in that we focus on those studies where moderation and mediation is investigated. The traditional approach has been to draw inferences about moderation and mediation by examining separate studies that does not test for the inference itself. For example, if one study shows that there is a positive relationship between construct $\mathrm{A}$ and $\mathrm{B}$, and another study that there is a relationship between $\mathrm{B}$ and $\mathrm{C}$, some may draw the erroneous conclusion that $\mathrm{B}$ is mediating between $\mathrm{A}$ and $\mathrm{C}$. In this case, the mediator variable has not been proven and the inference is based on speculation. A sound approach is to examine those studies that actually test the A-B-C relationship. We have now come to a 
point in time where studies that test a moderating or mediating variable between leadership and innovation have formed a substantive body of knowledge. This calls for a review of these variables which is now done in our review. Finally, since several scholars have called for a better understanding of the relationship between leadership and innovation (e.g., Byrne et al., 2009; Mumford et al., 2002; Shalley and Gilson, 2004), we discuss three mediating and moderating factors on leadership and innovation that has not yet been tested in a rigorous way.

Furthermore, in addition to our recognition of the importance of these moderating and mediating factors, we acknowledge the importance of multiple levels of analysis where organizational processes are likely nested in different levels (Drazin et al., 1999; Ford, 1996; Hemlin et al., 2008). For example, the effect of leaders on employees may depend on the climate of the team and the culture of the organization.

\section{Procedure}

\section{Literature search}

We conducted our literature search in several steps. During 2010 we searched for journal articles using the online databases PsycINFO, PsycARTICLES, ISI Web of Science, Social Services Abstracts, Sociological Abstracts, IBSS (International Bibliography of the Social Sciences), ASSIA (Applied Social Sciences Index and Abstracts), Business Source Premier, Econlit, and Regional Business News. We used the keywords leadership and innovation in our search. We also used the keyword creativity because it is occasionally used interchangeably with innovation in the literature. We analyzed each article's abstract in order to identify those articles that (1) were based on empirical studies, and (2) treated leadership as an independent variable, and innovation or creativity as a dependent variable. As we required that each journal article selected must have been peer reviewed, we did not consider unpublished articles and dissertations. At this point in our search we had identified 99 articles. $^{2}$

\section{Sample inclusion criteria}

First, we eliminated articles that were published before 1980 since we wanted to include only studies that (a) used advanced methodologies (adequate for mediatormoderator variable analyses) not in significant use before 1980 and that (b) reflected leaders' influence on employees with contemporary work attitudes and values. Second, we eliminated articles not indexed in the ISI Web of Science and

\footnotetext{
${ }^{2}$ We were unable to locate two articles we identified as of interest.
} 
articles with a journal impact factor $>1.0 .^{3}$ We specified this criterion in order to identify high quality journal articles that had gone through a more rigorous peer review process. Although questions have been raised about the IF, (e.g., Boor, 1982), it is generally recognized as a valid indicator of journal quality (Garfield, 2006). When a journal's IF is high, scholars are more inclined to submit their papers to that journal (Judge et al., 2007). More submissions provide a broader base for the selection of high quality research. Journal IF have been empirically related to higher rejection rates (Aarssen et al., 2008) and external assessments of journal quality (Saha et al., 2003).

However, we also wanted to ensure that we included highly influential articles published in journals with lower impact factors. It has been shown that interdisciplinary research such as innovation studies have been disadvantaged by high impact factor journals, which are more mono-disciplinary focused (Rafols et al., in press). For this purpose, we used the Google Scholar citation database to calculate a median of citations for our sample. This median was 77 citations (range 6 - 1291). We then searched the Google Scholar database, using the same above mentioned keywords, and included articles cited more or equal to 77 times. A total of 4 articles were added this way.

\section{Coding of dependent variables}

We coded the dependent variables of each article (creativity or innovation) as either (a) innovation-measures or (b) creativity-only measures. The basis for this coding was our definition of innovation. The articles in our review had to measure some aspect of implementation (i.e., the application of ideas such as new products or processes). Thus, according to this criterion, we could include articles in which the research aimed at measuring creativity, but not articles in which the research measured creativity only.

Bibliometric data for the reviewed journals is presented in Table 1. In the sample of 30 studies, the number of article cites ranged from 6 to 1291. On average the articles were cited 166 times, and the median of citations was 88 .

\section{Results}

In our sample of 30 studies, 17 studies measured transformational/transactional leadership, 3 studies measured leader-member exchange (LMX), and 10 studies

\footnotetext{
${ }^{3}$ The journal impact factor (IF) of a journal reflects the average number of citations per article in the journal during the two preceding years. Thus when a journal has a IF of 1 or more, each article in the journal has been cited on average one time or more times in the two preceding years (Garfield, 2006).
} 
Table 1. Journals reviewed in this article.

\begin{tabular}{lcccccc}
\hline Journal & $\begin{array}{c}\text { IF } \\
(2009)^{1}\end{array}$ & $\begin{array}{c}\text { Articles } \\
\text { in sample }\end{array}$ & & & Citations $^{2}$ & \\
\cline { 3 - 5 } & & & Range & Mean & Median \\
\hline Academy of Management Journal & 6.5 & 6 & $20-1291$ & 491 & 224 \\
European Journal of Innovation Management & n/a & 1 & 106 & - & - \\
Industrial Marketing Management & 1.3 & 1 & 94 & - & - \\
Journal of Applied Psychology & 3.8 & 1 & 48 & - & - \\
Journal of Applied Social Psychology & 0.77 & 1 & 126 & - & - \\
Journal of Business Research & 1.29 & 1 & 77 & - & - \\
Journal of Management & 4.4 & 2 & $97-110$ & 104 & 104 \\
Journal of Management Studies & 2.8 & 1 & 21 & - & - \\
Journal of Occupational and & 1.2 & 1 & 10 & - & - \\
Organizational Psychology & & & & & \\
Journal of Organizational Behavior & 2.0 & 1 & 17 & - & - \\
Journal of Product Innovation Management & 1.5 & 1 & 33 & - & - \\
Journal of World Business & 2.6 & 1 & 97 & - & - \\
Nonprofit Management and Leadership & n/a & 1 & 85 & - & - \\
Organizational Behavior and & 2.5 & 1 & 243 & - & - \\
Human Decision Processes & & & & & \\
Small Business Economics & 1.4 & 1 & 41 & - & - \\
Small Group Research & 0.68 & 1 & 77 & & - \\
Strategic Management Journal & 4.5 & 1 & 117 & - & - \\
The Leadership Quarterly & 2.2 & 7 & $6-296$ & 92 & 48 \\
\hline
\end{tabular}

Source: ${ }^{1}$ ISI Journal Citation Reports 2009 (2010).

Source: ${ }^{2}$ Google Scholar citation service (2012).

measured other leadership traits or behaviors. In the measurement of innovation, 12 of the 30 studies in the sample were conducted at the individual level, 4 studies at the team level, and 14 studies at the organizational level. The 15 studies that explicitly tested mediation and moderation variables between leadership and innovation are analyzed next.

\section{Individual level mediating and moderating factors}

Creative self-efficacy, mediator. It has been suggested that high levels of selfefficacy may contribute to increased motivation (Ford, 1996), greater eagerness to pursue individual ideas, and more effective use of cognitive resources (Thomas and Velthouse, 1990). Gong et al. (2009) recently tested this mediator and found that creative self-efficacy mediates the relationship between transformational leadership and employee innovative behavior. In an experimental study, Redmond et al. (1993) manipulated participants' feelings of self-efficacy by asking leaders to 
tell participants whether their scores in a pre-test were well above average or average. The participants who were told they scored above-average exhibited greater confidence in solving the problems subsequently posed as well as greater creativity related to the products produced.

Organizational based self-esteem (OBSE), moderator. OBSE refers to the employee's self-perceived value as an organizational member (Pierce et al., 1989). Some empirical evidence suggests that employees with low OBSE benefit from transformational leadership since they doubt whether their ideas or efforts are of value to the organization. Rank et al. (2009) found that OBSE moderates the relationship between leadership and individual innovativeness since the relationship is more important to employees with low levels of OBSE.

Self-presentation, moderator. Self-presentation, a core sub-dimension in the self-monitoring construct, refers to the way in which individuals engage in impression-management and modify their behavior in order to reflect the expectations from the social context (Gangestad and Snyder, 2000). High self-monitors tend to control and alter their behavior in order to present an image congruent with others' expectations. Such activity is less important for low self-monitors (Day et al., 2002). Rank et al. (2009) confirmed their hypothesis that self-presentation moderates the relationship between transformational leadership and individual innovativeness. The relationship was stronger for employees with low self-presentation. Rank et al. concluded that low self-monitors perform best when they are involved with an organization that supports them and allows them to act independently. Therefore they perform best working under transformational leaders who recognize their individual strengths and needs.

\section{Team level mediating and moderating factors}

Team reflection, mediator. Team reflection is a communication undertaking where team members collectively consider the team's goals, strategies, and processes. Somech (2006) found that leaders influenced team reflection that in turn promoted team innovation. In functionally heterogeneous teams, a participative leadership style was necessary to promote team reflection; in homogeneous teams, a more direct style was appropriate. These results point to team reflection as a mediator for leadership and team innovation.

Team heterogeneity, moderator. There are more opportunities for divergent thinking in heterogeneous teams where team members have diverse skill sets, knowledge, and cognitive problem solving styles (Hülsheger et al., 2009; Keller, 2001). Somech (2006) examined how leadership behavior, operationalized as participative and directive, affected functional heterogeneity and innovation outcomes. In participative leadership, for example, there is shared influence in 
decision-making and solicitation of new ideas from team members. In directive leadership, for example, there is a framework for decision-making and clear rules for behavior. Somech found that participative leadership has a moderating effect on team innovation only when functional heterogeneity is high; directive leadership has an effect when team heterogeneity is low.

Task characteristics, moderator. It is thought that complex tasks motivate employees to find creative ways to solve problems. With simpler tasks, employee fulfillment comes from solving problems using established knowledge and routines (Shalley and Gilson, 2004). In Oldham and Cummings' (1996) study, although job complexity was not directly related to the production of patents, an interaction showed that high job complexity combined with high non-controlling and supportive supervision resulted in more patents compared to other combinations. Thus, the challenge of the task may moderate the effects of leadership on innovation.

\section{Organizational level moderating factors}

Organizational structure. Factors related to the structure of an organization are believed to influence innovation performance (Thompson, 1965). In their study of 50 Taiwanese firms, Jung et al., (2008) found that when centralization and formalization are low, the influence of transformational leadership on organizational innovation is greater. Organizations with a high degree of centralization typically have decisionmaking authority concentrated at the upper management level (Damanpour, 1991). High formalization in organizations, where numerous routines and rules regulate the work, is thought to impede organizational innovation (Damanpour, 1991). For example, high centralization and formalization may reduce the autonomy of creative employees and teams (Jung et al., 2008), may hamper inter-functional and interdepartmental collaboration (Miller et al., 1988), and may constrain employees who depart from established practices (Dougherty and Hardy, 1996).

Organizational culture. The normative behavior expectations in an organization form the context in which individuals and teams are embedded. Risk-taking, experimentation, openness, trust, and autonomy are part of the organizational support that provides a foundation for innovation (Hunter et al., 2007; Mumford et al., 2002).

Recently, organizational support was examined in relation to leadership and innovation. Jung et al., (2008) found that organizational support (as defined by Siegel and Kaemmerer, 1978) moderated the CEO's leadership style and the firm's innovation. The extent of organizational support for innovation may influence the individual's willingness to undertake creative endeavors. Such willingness may in part depend on the perception of the consequences of such actions in the environment, as Yuan and Woodman (2010) and Scott and Bruce 
(1994) show. However, the findings are mixed regarding the role of organizational support. Gumusluoğlu and Ilsev (2009a) based their scale of organizational support on Scott and Bruce's (2004) study and could not show that support stemming from within the organization moderated the relationship between project leaders' transformational leadership and firms' sales of new products. Instead, support from, and collaboration with external institutions strengthened the relationship between transformational leadership and firm innovation.

\section{Ambiguous contingency factors}

Under this heading, we present two factors where mixed findings point to the fact that it still is unclear whether they are mechanisms in the relationship between leadership and innovation, i.e., if they act as mediating factors, or if they act as contingency factors and exert influence on leaders' discretion to lead innovative endeavors, i.e., if they act as moderating factors.

Psychological empowerment. Recent findings show that empowerment, the motivational construct consisting of meaning, competence, self-determination, and impact (Spreitzer, 1995), both moderates and mediates the relationship between leadership and innovation. Pieterse et al., (2010) found that, only for individuals with high levels of psychological empowerment, transformational leadership was positively related to innovative behavior and transactional leadership was negatively related to innovative behavior. However, Jung et al. (2003) and Jung et al., (2008) could not show that psychological empowerment at the organizational level moderated transformational leadership and organizational innovation. Furthermore, when creativity is the criterion variable, psychological empowerment has been shown to mediate between transformational leadership (Gumusluoğlu and Ilsev, 2009b) empowering leadership (Zhang and Bartol, 2010), and individual creativity. Thus, it is unclear whether leaders influenceteam members' psychological empowerment, as suggested by Gumusluoğlu and Ilsev (2009b), or if the construct is independent of leadership, as argued by Pieterse et al. (2010).

Team climate. It is assumed that leaders generally have a significant influence in creating a climate conducive to team innovation by, for instance, acting as role models, supporting ideas, and participating in the work (Isaksen and Tidd, 2006). Consistent with these ideas, team climate appears to be a mediator between leadership and innovation as West et al., (2003) have shown. In their study, team climate, measured by Team Climate Inventory (TCI) (Anderson and West, 1998), partially mediated the effects of leadership influence on team innovation in selfmanaged teams. However, in a more recent study, Eisenbeiss et al., (2008) found that team climate moderated the positive relationship of transformational leadership and innovation. They concluded that leaders may be an important part of team 
innovation, but without shared norms and ambitions of excellence, leaders' influence is limited. These ambiguous findings point to a more profound problem in conceptualizing innovative climate. It is still unclear whether the leader primarily influences the team climate or is influenced by it.

\section{New moderators and mediators}

In this section, we propose and discuss three new mediators and moderators between leadership and innovation at the individual and team levels. Some of these factors are known to the extant literature and have been tested as predictors for innovation. However, the factors proposed in this section have not yet been tested as mediators or moderators between leadership and innovation.

\section{Individual level}

External work contacts, mediator. The literature has emphasized the effect of external work contact networks on innovation (e.g., Tidd et al., 2001). This research has found that the number and frequency of such contacts relate to individual innovative work behavior (De Jong and Den Hartog, 2010). De Jong (2007) hypothesized that the number of external contacts moderated the relationship between leadership and innovation, but was unsuccessful in finding evidence to support this relationship. However, Mumford et al. (2002) and Woodman et al. (1993) state that it is the job of leaders to organize and promote the information flow in groups. LMX theory stipulates that good leaders add their resources to those of their team members (Liden and Maslyn, 1998). Thus, the leader may influence whether and when individuals seek contacts external to the group or organization. These external contacts may stimulate innovative endeavors (Hemlin and Olsson, 2011).

Personal initiative, mediator. Personal initiative refers to the extent to which the individual engages in proactive and long-term, goal-oriented behaviors where actions are taken that extend beyond the terms specified in the formal work contract (Frese et al., 1997). An individual's degree of personal initiative and proactiveness has been linked to innovation (Seibert et al., 2001). According to Frohman (1999), leaders may influence such behavior. Transformational leadership theory posits that transformational leaders motivate team members to make extra-contractual efforts (Bass and Riggio, 2006). Similarly, a high quality LMX relationship may have this effect when a team member is given more responsibility and is placed in a position of greater trust (Liden and Maslyn, 1998).

\section{Team level}

Group developmental stages, moderator. Various researchers have studied the different stages in group development (e.g., Arrow et al., 2004; Tuckman, 1965; 
Wheelan, 2005). In these group stages, cohesion, commitment, norm conformity, and goal related behavior may fluctuate (Tuckman, 1965). Leaders certainly influence the progression of these stages. Yet it appears that group members respond to leader influence differently in each developmental stage. In the integrative model of group development (Wheelan, 2005), leader influence depends on the group stage. In the first of four stages in this model, members tend to follow most of the direction provided by their leaders, but in the second stage, as they increasingly challenge this direction, conflict arises around issues such as roles, group organizing, and goals. In the third and fourth stages, when group members are again more open to leaders' influence, performance tends to be highest (e.g., Wheelan and Tilin, 1999). In this understanding of group development, the group dynamics involved in the different stages may limit leaders' influence to those processes involving innovation, such as ideation and idea implementation.

\section{Conclusions}

\section{The When and the How: Contingency factors and mechanisms related to innovation}

This article reviewed 30 peer-reviewed articles 1980-2011 from the Web of Science's highest rated journals. Our aim was to investigate the contingency factors and mechanisms between leadership and innovation, i.e., the moderating and mediating variables.

Moderating variables. In assessing the contingency factors related to when leaders may influence innovation, we conclude that the relationship between leadership and innovation appears strongest in organizations that have a supportive culture for innovation (Jung et al., 2008) and where organizational structures are de-formalized and de-centralized. In such organizations, both leaders and employees are freer to engage in creative work (Damanpour, 1991; Jung et al., 2008). Furthermore, teams that are heterogeneous and work on complex tasks have the highest capability for innovation. Such teams require supportive and noncontrolling leadership that includes them in decision-making. Finally, leaders can promote innovative behavior among employees who have low organizational selfesteem and low self-presentation (Rank et al., 2009).

Mediating variables. In addressing the question of how leaders stimulate innovation (i.e., through the use of mediating variables) we conclude that leaders may stimulate innovation on the individual level by influencing creative self-efficacy (Gong et al., 2009; Redmond et al., 1993). Moreover, leaders may also stimulate innovation by introducing norms that encourage team reflection processes, e.g., by means of debates, open communication, and divergent thinking (Somech, 2006). 


\section{Implications for leaders of innovation}

(Hemlin et al., 2008) argued that a creative knowledge environment (CKE) should be established and promoted in organizations that wish to develop innovative products and processes. To a great extent, establishing a CKE is a leader responsibility. It is crucial for leaders to identify the specific environmental factors conducive to innovation and creativity. One may think of a CKE as a set of nested layers of environmental factors in an organization where individual and team creative activities are undertaken. In such environments, it is clear that the work design, as well as the social and organizational characteristics at the team and organizational levels, have a crucial influence on the innovation processes. This influence is implemented through adopting supportive cultures, informal structures, and organizational slack.

Our literature research suggests there are a number of steps leaders may take when creating a CKE. First, upper management and their teams should establish an innovation policy that is promoted throughout the organization. It is necessary that the organization through its leaders communicate to employees that innovative behavior will be rewarded (Mumford and Gustafson, 1988). Second, when teams are composed, the potential for team innovation should be a consideration in selecting the team members. One team characteristic that seems to promote innovativeness is team heterogeneity (Reiter-Palmon and Illies, 2004). However, if the team is too heterogeneous, tensions may arise. On the other hand, when heterogeneity is too low, more directive leadership is required to promote team reflection, for example, by encouraging discussion and disagreement. Third, if creativity and innovativeness are to flourish, leaders should promote a team climate of emotional safety, respect, and joy through emotional support and shared decision-making (Ekvall and Arvonen, 1991; Hemlin et al., 2008). Fourth, it is essential that individuals and teams have autonomy and space for idea generation and creative problem solving (Pelzand Andrews, 1966). Fifth, time limits for idea creation and problem solutions should be set, particularly in the implementation phases (Basadur, 2004). Finally, team leaders, who have the expertise, should engage closely in the evaluation of innovative activities (Mumford et al., 2002).

\section{Limitations of the study}

First, this paper is limited by its sampling procedures. We chose 1980 as our cutoff year because we wanted to include only research studies using advanced methodologies that were suitable for mediator-moderator analyses. We have no knowledge whether our results might have differed had we also included research studies published prior to 1980 . Our findings may have also been affected by our 
requirement that the studies had to be of high quality (published in journals with IF $>1.0$ ). We omitted a few studies that tested mediator-moderator relationships but were published in lesser-ranked journals. Although we may also have omitted some recent high quality studies because they were published in dissertations or books, we considered this omission to be of less concern since it is likely those studies will be published at some future date in quality journals and will be included in future reviews.

Second, in the reviewed articles, theories and concepts were conceptualized, operationalized, measured and analyzed slightly differently, which then may affect the aggregated conclusions we reached. The risk is our conclusions may be too compartmentalized and/or oversimplified. This is an inherent problem of reviews of research literature.

\section{Suggestions for future research on leadership and innovation}

In addition to further research on the two ambiguous factors that we found (i.e., psychological empowerment and team climate), we suggest the following three areas for future research on leadership and innovation.

Stages of the innovation process. Further research is needed into how the innovation process interacts with leaders' efforts. This process consists of problem construction or definition (Reiter-Palmon and Illies, 2004), idea generation, evaluation, and promotion (Basadur, 2004), and of the planning, championing, and securing of funds for implementation (Scott and Bruce, 1994; Tushman and Nadler, 1986). The role of leaders is to provide a structure for the innovation process. In the early stages of innovation, leaders may have to take a divergent and explorative approach to problem construction and ideation in which knowledge and ideas are broadly integrated. Similarly, a convergent approach, focused on moving forward may be more suitable in the later stages where implementation is the focus. However, there is little research on how leaders may facilitate these cognitive and emotional processes in individuals and in teams (cf. Isaksen and Tidd, 2006).

Destructive leadership. Very few studies in our review deal with how leaders obstruct or impede innovation. For example, leaders who monitor their employees too closely and give little support (Oldham and Cummings, 1996), who do not give them sufficient autonomy (Krause, 2004), who exclude them from the decision process, and who squelch new ideas (Somech, 2006) may stifle creativity and innovativeness. Therefore, research is needed on when and how leadership behaviors are detrimental to innovation (Shaw et al., 2011).

Leadership for radical and incremental innovation. More research is also needed on leadership when the goal is to create new and novel products 
(i.e., radical innovation) or when the goal is to expand and refine existing products (incremental innovation) (Tidd et al., 2001). While Jansen et al. (2009) found a negative correlation between transactional leadership and radical innovation, their study showed that transactional leadership is positively related to incremental types of innovation. Thus, leaders who are more transaction-oriented may be more successful in promoting innovation when they work toward achieving the innovation goal by guiding employees towards refinements of existing products and increasing the efficiency of existing practices and processes. The distinction between incremental and radical innovation may thus be an important issue in future research and in theoretical modeling of leadership and innovation (see e.g., Isaksen and Tidd, 2006).

Methodology. If moderating and mediating variables are addressed in studies in which leadership and management of innovation in organizations are examined, it is necessary to apply multi-level modeling and structural equation models. Such models are appropriate for analyzing the complex interrelationships of leadership and innovation.

\section{References}

References marked with * were included in the selection of articles for this review.

Aarssen, LW, T Tregenza, AE Budden, CJ Lortie, J Koricheva and R Leimu (2008). Bang for your buck: Rejection rates and impact factors in ecological journals. The Open Ecology Journal, 1, 14-19.

Amabile, TM, R Conti, H Coon, J Lazenby and M Herron (1996). Assessing the work environment for creativity. Academy of Management Journal, 39, 1154-1184.

Anderson, N, CKW De Dreu and BA Nijstad (2004). The routinization of innovation research: A constructively critical review of the state-of-the-science. Journal of Organizational Behavior, 25, 147-173.

Anderson, NR and MA West (1998). Measuring climate for work group innovation: Development and validation of the team climate inventory. Journal of Organizational Behavior, 19, 235-258.

*Aragón-Correra, JA, VJ García-Morales and E Cordón-Pozo (2007). Leadership and organizational learning's role on innovation and performance: Lessons from Spain. Industrial Marketing Management, 36, 349-359.

Arrow, H, MS Poole, KB Henry, S Wheelan and R Moreland (2004). Time, change and development: The temporal perspective on groups. Small Group Research, 35, 73-105.

Avolio, BJ, BM Bass and DI Jung (1999). Re-examining the components of transformational and transactional leadership using the multifactor leadership questionnaire. Journal of Occupational and Organizational Psychology, 72, 441-462. 
Basadur, M. (2004). Leading others to think innovatively together: Creative leadership. The Leadership Quarterly, 15, 103-121.

Bass, BM and RE Riggio (2006). Transformational Leadership, 2nd edn. Mahwah, NJ: Lawrence Erlbaum Associates.

*Basu, R and SG Green, (1997). Leader-member exchange and transformational leadership: An empirical examination of innovative behaviors in leader-member dyads. Journal of Applied Social Psychology, 27, 477-499.

Boor, M (1982). The citation impact factor: Another dubious index of journal quality. American Psychologist, 37, 975-977.

Burns, T and G Stalker (1961). The Management of Innovation. London: Tavistock.

*Burpitt, WJ and WJ Bigoness (1997). Leadership and innovation among teams: The impact of empowerment. Small Group Research, 28, 414-423.

Byrne, CL, MD Mumford, JD Barrett and WB Vessey (2009). Examining the leaders of creative efforts: What do they do, and what do they think about? Creativity and Innovation Management, 18, 256-268.

*Chen, G, D Tjosvold and C Liu (2006). Cooperative goals, leader people and productivity values: Their contribution to top management teams in China. Journal of Management Studies, 43, 1177-1200.

Csikszentmihaly, M (1999). Implications of a system perspective for the study of creativity. In RJ Sternberg (Ed.), Handbook of creativity, pp. 313-334. Cambridge, UK: Cambridge University Press.

*Czarnitzki, D and K Kraft (2004). Firm leadership and innovative performance: Evidence from seven EU countries. Small Business Economics, 22, 325-332.

Damanpour, F. (1991). Organizational innovation: A meta-analysis of effects of determinants and moderators. Academy of Management Journal, 34, 555-590.

Day, DV, DJ Schleicher, AL Unckless and NJ Hiller (2002). Self-monitoring personality at work: A meta-analytic investigation of construct validity. Journal of Applied Psychology, 87, 390-401.

De Jong, JPJ (2007). Individual innovation. The Connection Between Leadership and Employees' Innovative Work Behavior. Unpublished doctoral dissertation. Amsterdam: University of Amsterdam.

*De Jong, JPJ and DN Den Hartog (2007). How leaders influence employees' innovative behavior. European Journal of Innovation Management, 10, 41-64.

De Jong, J and D Den Hartog (2010). Measuring innovative work behavior. Creativity and Innovation Management, 19, 23-36.

Dougherty, D and C Hardy (1996). Sustained product innovation in large, mature organizations: Overcoming innovation-to-organization problem. Academy of Management Journal, 39, 1120-1153.

Drazin, R, MA Glynn and RK Kazanjian (1999). Multilevel theorizing about creativity in organizations: A sense making perspective. Academy of Management Review, 24, 286-307. 
*Eisenbeiss, SA, D van Knippenberg and S Boerner (2008). Transformational leadership and team innovation: Integrating team climate principles. Journal of Applied Psychology, 93, 1438-1446.

Ekvall, G and K Arvonen (1991). Change-centered leadership: An extension of the twodimensional model. Scandinavian Journal of Management, 7, 17-26.

*Elenkov, DS, W Judge and P Wright (2005). Strategic leadership and executive innovation influence: An international multi-cluster comparative study. Strategic Management Journal, 26, 665-682.

*Elenkov, DS and IM Manev (2005). Top management leadership and influence on innovation: The role of sociocultural context. Journal of Management, 31, 381-402.

*Elenkov, DS and IM Manev (2009). Senior expatriate leadership's effects on innovation and the role of cultural intelligence. Journal of World Business, 44, 357-369.

Elkins, T and RT Keller (2003). Leadership in research and development organizations: A literature review and conceptual framework. The Leadership Quarterly 14, 587-606.

Ford, CM. (1996). A theory of individual creative action in multiple social domains. Academy of Management Review, 21, 1112-1142.

Frese, M, D Fay, T Hilburger, K Leng and A Tag (1997). The concept of personal initiative: Operationalization, reliability and validity in two German samples. Journal of Occupational and Organizational Psychology, 70, 139-161.

Frohman, AL (1999). Personal initiative sparks innovation. Research-Technology Management, 42, 32-48.

Gangestad, SW and M Snyder (2000). Self-monitoring: Appraisal and reappraisal. Psychological Bulletin, 126, 530-555.

Garfield, E. (2006). The history and meaning of the journal impact factor. The Journal of the American Medical Association, 295, 90-93.

*Gong, Y, J-C Huang and J-L Fahr (2009). Employee learning orientation, transformational leadership, and employee creativity: The mediating role of employee creative self-efficacy. Academy of Management Journal, 52, 765-778.

Google Scholar Citation Service. (2012). Available at http://www.google.com/scholar.

*Gumusluoğlu, L and Ilsev A (2009a). Transformational leadership and organizational innovation: The roles of internal and external support for innovation. The Journal of Product Innovation Management, 26, 264-277.

*Gumusluoğlu, L and Ilsev, A (2009b). Transformational leadership, creativity, and organizational innovation. Journal of Business Research, 62, 461-473.

Hemlin, S (2006a). Creative knowledge environments for research groups in biotechnology: The influence of leadership and organizational support in universities and business companies. Scientometrics, 67, 121-142.

Hemlin, S (2006b). Managing creativity in academic research. How could creative action and management be reconciled in research? Science Studies, 19, 3-12.

Hemlin, S, CM Allwood and BR Martin (2008). Creative knowledge environments. Creativity Research Journal, 20, 196-210. 
Hemlin, S and L Olsson (2011). Creativity-stimulating leadership: A critical incident study of leaders' influence on creativity in research groups. Creativity and Innovation Management, 20, 49-58.

Hülsheger, UR, N Anderson and JF Salgado (2009). Team-level predictors of innovation at work: A comprehensive meta-analysis spanning three decades of research. Journal of Applied Psychology, 94, 1128-1145.

Hunt, JG and JA Conger (1999). From where we sit: An assessment of transformational and charismatic leadership research. The Leadership Quarterly, 10, 335-343.

Hunter, ST, KE Bedell and MD Mumford (2007). Climate for creativity: A quantitative review. Creativity Research Journal, 19, 69-90.

Isaksen, S and J Tidd (2006). Meeting the Innovation Challenge: Leadership for Transformation and Growth. Chichester: John Wiley and Sons Ltd.

ISI Journal Citation Reports.(2009). Available at http://apps.isiknowledge.com.

*Jansen, JJP, D Vera and M Crossan (2009). Strategic leadership for exploration and exploitation: The moderating role of environmental dynamism. The Leadership Quarterly, 20, 5-18.

*Jaskyte, K (2004). Transformational leadership, organizational culture, and innovativeness in nonprofit organizations. Nonprofit Management and Leadership, 15, 153-168.

Judge, TA, DM Cable, AE Colbert and SL Rynes (2007). What causes a management article to be cited-article, author or journal? Academy of Management Journal, 50, 491-506.

*Jung, D. I., C Chow and A Wu (2003). The role of transformational leadership in enhancing organizational innovation: Hypotheses and some preliminary findings. The Leadership Quarterly, 14, 525-544.

*Jung, D, A Wu and CW Chow (2008). Towards understanding the direct and indirect effects of CEOs' transformational leadership on firm innovation. The Leadership Quarterly, 19, 582-594.

Keller, RT (2001). Cross-functional project groups in research and new product development: Diversity, communications, job stress, and outcomes. Academy of Management Journal, 44, 547-555.

*Krause, DE (2004). Influence-based leadership as a determinant of the inclination to innovate and of innovation-related behaviors: An empirical investigation. The Leadership Quarterly, 15, 79-102.

Liden, RC and Maslyn, JM (1998). Multidimensionality of leader-member exchange: An empirical assessment through scale development. Journal of Management, 24, 43-72.

*Ling, Y, Z Simsek, MH Lubatkin and JF Veiga (2008). Transformational leadership's role in promoting corporate entrepreneurship: Examining the CEO-TMT interface. Academy of Management Journal, 51, 557-576.

*Makri, M and TA Scandura (2010). Exploring the effects of creative CEO leadership on innovation in high-technology firms. The Leadership Quarterly, 21, 75-88.

Miller, D, C Dröge and J-M Toulouse (1988). Strategic process and content as mediators between organizational context and structure. Academy of Management Journal, 32, 544-569. 
Mumford, MD and SB Gustafson (1988). Creativity syndrome: Integration, application, and innovation. Psychological Bulletin, 103, 27-43.

Mumford, MD, GM Scott, B Gaddis and JM Strange (2002). Leading creative people: Orchestrating expertise and relationships. The Leadership Quarterly, 13, 705-730.

OECD (2005). Oslo Manual. Guidelines for Collecting and Interpreting Innovation Data (3rd edn.), Paris: OECD.

Oke A, N Munshi and FO Walumba, (2009). The influence of leadership on innovation processes and activities. Organizational Dynamics, 38, 64-72.

*Oldham, GR and A Cummings (1996). Employee creativity: Personal and contextual factors at work. Academy of Management Journal, 39, 607-634.

Olsson, L, S Hemlin and A Pousette (in press). A multi-level analysis of leader-member exchange and creative performance in research groups. The Leadership Quarterly.

*Osborn, RN and R Marion (2009). Contextual leadership, transformational leadership and the performance of international innovation seeking alliances. The Leadership Quarterly, 20, 191-206.

Pelz, D and F Andrews (1966). Scientists in Organizations: Productive Climates for Research and Development. New York: Wiley.

Pierce, JK, DG Gardner, LL Cummings and RB Dunham (1989). Organization-based selfesteem: Construct definition, measurement and validation. Academy of Management Journal, 32, 622-648.

*Pieterse, AN, D van Knippenberg, M Schippers and D Stam (2010). Transformational and transactional leadership and innovative behavior: The moderating role of psychological empowerment. Journal of Organizational Behavior, 31, 609-623.

Pirola-Merlo, A and L Mann (2004). The relationship between individual creativity and team creativity: Aggregating across people and time. Journal of Organizational Behavior, 25, 235-257.

*Rank, J, NE Nelson, TD Allen and X Xu (2009). Leadership predictors of innovation and task performance: Subordinates' self-esteem and self-presentation as moderators. Journal of Occupational and Organizational Psychology, 82, 45-489.

*Redmond, MR, MD Mumford and R Teach (1993). Putting creativity to work: Effects of leader behavior on subordinate creativity. Organizational Behavior and Human Decision Processes, 55, 120-151.

Reiter-Palmon, R and JJ Illies, (2004). Leadership and creativity: Understanding leadership from a creative problem-solving perspective. The Leadership Quarterly, 15, 55-77.

Saha, S, S Saint and DA Christakis (2003). Impact factor: A valid measure of journal quality? Journal of the Medical Library Association, 91, 42-46.

*Scott, SG and RA Bruce (1994). Determinants of innovative behavior: A path model of individual innovation in the workplace. Academy of Management, 37, 580-607.

Seibert, SE, MK Kraimer and JM Crant (2001). What do proactive people do? A longitudinal model linking proactive personality and career success. Personnel Psychology, 54, 845-874. 
Shalley, CE and LL Gilson (2004). What leaders need to know: A review of social and contextual factors that can foster or hinder creativity. The Leadership Quarterly, 15, 33-53.

Shaw, JB, A Erickson and M Harwey (2011). A method for measuring destructive leadership and identifying types of destructive leaders in organizations. The Leadership Quarterly, 22, 525-590.

*Shin, SJ and J Zhou (2003). Transformational leadership, conservation, and creativity: Evidence from Korea. Academy of Management Journal, 46, 703-714.

Siegel, SM and WF Kaemmerer, (1978). Measuring the perceived support for innovation in organizations. Journal of Applied Psychology, 63, 553-562.

*Somech, A (2006). The effects of leadership style and team process on performance and innovation in functionally heterogeneous teams. Journal of Management, 32, $132-157$.

Spreitzer, GM (1995). Psychological empowerment in the work place: Dimensions, measurement and validation. Academy of Management Journal, 38, 1442-1465.

Thomas, KW and BA Velthouse (1990). Cognitive elements of empowerment: An "interpretive" model of intrinsic task motivation. Academy of Management Review, $15,666-681$.

Thompson, VA (1965). Bureaucracy and innovation. Administrative Science Quarterly, $10,1-20$.

Tidd, J, P Bessant and K Pavitt (2001). Managing Innovation. Integrating Technological, Market and Organizational Change. Chichester: Wiley.

Tierney, P, SM Farmer and GB Graen (1999). An examination of leadership and employee creativity: The relevance of traits and relationships. Personnel Psychology, 52, 591-620.

Tuckman, BW (1965). Developmental sequence in small groups. Psychological Bulletin, 63, 384-399.

Tushman, M and D Nadler (1986). Organizing for innovation. California Management Review, 28, 74-92.

*West, MA, CS Borril, JF Dawson, F Brodbeck, DA Shapiro and B Haward (2003). Leadership clarity and team innovation in health care. The Leadership Quarterly, 14, 393-410.

Wheelan, S (2005). Group Processes: A Developmental Perspective, 2nd edn. Boston, MA: Allyn and Bacon.

Wheelan, S and F Tilin (1999). The relationship between faculty group development and school produ ctivity. Small Group Research, 30, 59-81.

Woodman, RW, JE Sawyer and RW Griffin (1993). Toward a theory of organizational creativity. Academy of Management Review, 18, 293-321.

*Yuan, F and RW Woodman (2010). Innovative behavior in the workplace: The role of performance and image outcome expectations. Academy of Management Journal, 53, $323-342$. 
Yukl, G (1999). An evaluation of conceptual weaknesses in transformational and charismatic leadership theories. The Leadership Quarterly, 10, 285-305.

Zhang, X and KM Bartol (2010). Linking empowering leadership and employee creativity: The influence of psychological empowerment, intrinsic motivation, and creative process engagement. Academy of Management Journal, 53, 107-128. 